\title{
Developing as an academic leader in a university of technology in South Africa: Dealing with enabling and constraining teaching and learning environments
}

\author{
'Mabokang Monnapula-Mapesela \\ Central University of Technology, Free State
}

(Received 2 February 2017; accepted 1 December 2017)

\begin{abstract}
While the South African legislation is an enabler for equity, inclusiveness, social justice and the advancement of women for academic leadership roles, institutional cultures and structures are often debilitating. This paper presents the development trajectory of a Black woman as an academic development leader in a South African University of Technology. It examines structural and cultural factors acting as enablers or constraints to leadership development and career advancement for Black women. It analyses dominant structural frames and undertakings of different University stakeholders (agents), which cause stagnation and resistance to morphogenesis and government's transformation agenda. Using Participatory Narrative Inquiry (PNI), I narrate personal experiences and insights as a participant researcher. I interrogate the experiences, observations and influence of various structural and cultural modalities within Margaret Archer's (1995) social realist framework of structure, culture and agency. I highlight the implications of these for development of a Black female academic development leader.
\end{abstract}

Keywords: career advancement, equity and transformation, Higher Education, narrative inquiry, resistant cultures.

The drastic systemic changes and transformation that took place in South Africa post-1994 are legitimate. The underlying rationale for the myriad of policy prerogatives in the South African Higher Education (HE) sector was predominantly redress of the inequities of the apartheid past by addressing and responding to the needs of all stakeholders. This includes providing women, especially Black women, with equitable career and development opportunities. However, two decades into democracy strides in this development in particular have been minimal (CHE, 2016) due to, amongst other things, limited institutional progress and debilitating emerging institutional cultures and structures.

Literature argues that the HE system in South Africa is still marred by obvious contradictions and discrepancies regarding the quality of transformation and achievement of equity targets, particularly for qualified Black academics and women in management positions (Boughey and McKenna, 2015; Luckett, 2010). Boughey and McKenna (2015) analysed the different layers of the HE system and the gains of the previous cycle of 
institutional quality audits using Roy Bhaskar's (1989) ideology of a layered ontology, and Margaret Archer's complimentary social realist framework of structure, culture and agency. In this analysis, these authors unveiled obvious structural changes (morphogenesis) in the HE system, some form of agential change (morphogenesis), yet morphostasis (very little to no change) at the level of culture. Government's widening of access to HE has been followed by commensurate provision of structures and resources to support cultural change. However, institutional cultures are still unsupportive, while the agential willpower of those entrusted to uphold the transformative notion of quality within the institutions is still low (Harvey, 2006). This is contrary to what would truly contribute to bringing about social equity and transformation.

Mamphele Ramphele, in her 2008 book, Laying ghosts to rest: Dilemmas of the transformation in South Africa, argues that the promotion of equity and excellence in Higher Education depends on informed decisions to set up relevant structures, and an enabling culture. She argues that setting up equal-opportunity-access programmes for both staff and students, providing academic support for student and staff development, as well as introducing programmes geared at changing institutional cultures to render them inclusive of diversity in its various forms, are some ways in which universities can show that their efforts for promotion of equity are sincere.

Institutional cultures and structures constraining transformation and undermining the support of Black women at universities are remnants of the old apartheid prejudices (Naicker, 2013). These include inequality and uneven distribution of social and economic resources; racial discrimination; separate development; male domination, subjugation and relegation of women to the back pews; invisible boundaries and identity formations; 'gentlemen's clubs'; and party politics within higher education institutions (HEIs). These ideologies affect mostly Black female academics (Naicker, 2013). Hence, the focus of this paper is a personal narrative trajectory of a Black female Associate Professor, who is also an academic development leader in a transforming university of technology in South Africa.

Often times, Black academics - especially women - allow tensions of identity to determine and dictate their success in Higher Education (Mainah, 2016; Naicker, 2013). According to Walker (1998), such identity tensions are constructed at sites of complex and chaotic struggles, and at the nexus of multiple subject positions within highly polarised contexts (mostly social and political). Those who are subjected to these tensions react in various ways that often constrain their own development. Some dwell on self-pity and perceive themselves as inadequate; some blame others for the difficult journey of development they must endure to reach positions of power, while some make assumptions that higher positions in academia are just not accessible to Black women. Those women who persist and eventually hold positions of power often struggle with self-knowledge and selfawareness, and find it difficult to celebrate their uniqueness, performance and success (Mainah, 2016). The success they enjoy comes at a price, because although this success is hard-earned through struggle, women are made to think that they do not deserve it. Many people, especially the territorial occupants who claim to be the only legitimate knowledgecreators (Maton, 2014; Mainah, 2016) in HEIs view such success with scepticism (Mabokela, 2012). White women who have enjoyed dominance and HE stakes without interference from Black women, and recently Black male academics who have gained recognition as legitimate 
knowers, often perceive Black female academics as voiceless, passive, invisible and inarticulate agents (Lewis, 1992, in Naicker, 2013) who take no initiative for their own development. New forms of power relations and discrimination, and academic bullying due to patriarchal ideologies have emerged, and these build invisible boundaries that are impenetrable to the underdog (Naicker, 2013).

As a survival mechanism, I favour celebrating achievements and milestones, no matter how minimal they may be. I enjoy turning disadvantage and subtle or overt oppressive undertakings into successes and celebrated moments. However, I cannot ignore the slow or sometimes flawed implementation of policy; transformation and policy implementation inertia (Badat, 2015); and the regression of the system in addressing issues that stifle the development of Black female academics. Disappointing statistics of Black female professors and women in senior and executive leadership positions at my institution, and many other universities in South Africa, are testimony to this. Black female professors and leaders are conspicuously absent at most universities (Naicker, 2013). According to Africa Watch of August, 2014, there were only 34 Black female professors at South African universities. My institution is a product and mirror image of the national context. Currently, out of a total of 40 professors at my institution (CUT Statistics-at-a-Glance, 2017), there are only two Black female professors, regardless of institutional policy aspirations set by the University to increase these figures by 2020 (Academic Plan, 2014 - 2020). For eight years of my tenure, I was one of the two Black female professors out of a total of 40 full professors and associate professors (CUT Annual Report, 2016).

\section{Theoretical framework}

I use Margaret Archer's (1995) social realism and her morphogenetic analytical framework of structure, culture and agency as a lens through which to examine various structural, cultural and agential modalities that have influenced and continue to shape my role and growth as an academic development leader in enabling and constraining ways. For the purposes of this paper, I focus only on the following: expansive scope and associated complexities of academic development (AD) work without adequate support structures (Brew, 2007), and lack of agency by key agents and various dominant cultures, which undermine females in academia (Mabokela, 2012). Some of these cultures are largely social formations and remnants of the past apartheid ideology, while others are a result of ongoing transformation. Significantly, the influences of these modalities on my journey since I commenced work as a leader are analysed. I focus on my induction, and my journey to becoming an AD leader; the pains and gains that I endured through gender stereotyping, male domination, subtle discrimination, as well as support - or the lack thereof - by various agents during my tenure. As I am not alone in my position within higher education, it is my hope that analysing my own journey in this way will provide insights into the possible career trajectories and struggles of women in academia, particularly Black women. I use my story to make a larger argument about cultural change in Higher Education around other women, and Black women especially.

Archer's social realist theory (Archer, 1995, 1996) permits exploration of causal links between the different strata of the social world. It is used extensively in Higher Education to investigate the context at macro, meso and micro levels (Donati, 2011: 136). Explicit 
consideration of both systemic and cultural contexts improves the likelihood of providing complete explanations why a certain status quo prevails (Ashwin, 2008; Quinn, 2012a). Archer's $(1995,1996)$ stratification of the world and things into structure, culture and agency, each with distinctive emergent properties and causal powers, irreducible to one another, allows a deep analysis of each without any conflation. However, it is the analysis of their interplay that brings a better understanding of what causes or constrains agential change in people.

I make explicit the impact of my institution's context on my development and career trajectory, with a view to erase any 'taken-for-granted' assumptions about the often slow progress that Black female academics endure. I highlight my personal experiences of how unchanging systems and cultures or morphostasis (Archer, 1996) constrain development. Key questions asked in this personal inquiry are: 1) what structures had an impact on my career growth and how I experienced these structures as enablers or constraints; and 2) what has been the role played by the dominant institutional culture(s) on my growth, and how has this enabled or constrained my career growth.

Before I analyse selected structures and cultures that have had the greatest impact on my trajectory enabling and sometimes constraining my development, I present the context of my institution and the structural changes that took place after 2004 when it became a university in response to the national transformation agenda.

\section{Changing from a Technikon to a University of Technology: implications for AD work}

After 1994, government set out a massive transformation agenda to achieve a single, wellcoordinated HE system that is non-racialised, inclusive and responsive to the needs of the country and all South Africans, regardless of creed or status (DoE, 1997). HEIs in South Africa were differentiated into three types of universities: traditional universities, universities of technology (UoTs) and comprehensive universities, each with a differentiated role and function. This change entailed not only institutional role changes, but also major structural and cultural reforms, with far-reaching implications. Although the effects of this major transformation were experienced by all universities, UoTs can be argued to have experienced more pervasive change. The spinoffs of this differentiation have been slow to realise, and there are still intricate unintended power struggles entrenched in past identities and political history.

Prior to 1994, what is now the Central University of Technology, where I now work, was a Whites-only Technikon, and, like all previously White institutions, its role and mission were entrenched in the apartheid ideology of separate development. At the advent of democracy, this status changed as access was provided to all students and staff, regardless of race. Since becoming a University, it has grown substantially in size and shape, from approximately 3000 to over 16000 students, with the majority enrolled at its main campus in Bloemfontein. This 'massification' has had significant implications for the structures, institutional culture, staff, academic work and support. Resources have been stretched to capacity, threatening the quality of teaching and learning, as well as support for students. This has resulted in an unending experimental transformation of its structures (including $\mathrm{AD})$, systems, programmes and staffing complement, with an attempt to realign its processes. However, this has caused job uncertainties for many AD practitioners at the institution. While 
in many instances the University seems to be open to a total overhaul by engaging more deeply with transformation discourses as a basis for determining its emerging role and relevance, in some cases old institutional structures and cultures resist change (Archer, 1996), and these constrain the national and institutional transformation agendas (Boughey and McKenna, 2015).

As a UoT, the Central University of Technology has had to acquaint itself with the culture espoused by government through Higher Education legislation, and the development and implementation of many institutional policies. The Higher Education Qualifications Subframework (HEQSF) has become the most impactful policy in the UoT sector. Its promulgation has caused a total 'disruption' for curriculum design and development, forcing UoT academics who have had no prior training or engagement with curriculum development out of their comfort zones. The implications for AD work have become more complex, as AD leaders are expected to be strategic knowledgeable others (Vygotsky, 1978) who negotiate change and guide institutions through the transitional period.

The deeply entrenched technikon ideologies and philosophies contribute to a culture of resistance towards change and transformation among most academics. It makes it difficult for any $\mathrm{AD}$ leader to infuse cultural change through new policies; new demands for quality teaching and learning; as well as curriculum transformation, to mention only a few change imperatives. This is made more complicated when the AD leader is a Black woman in a historically White institution struggling with its identity.

\section{Methodology}

In this paper, I use Participatory Narrative Inquiry (PNI) methodology to explore the realities of a Black female leader working in a transforming HE system in South Africa. Accordingly, this study is auto-ethnographic in nature, and it adheres to the norms of narrative inquiry (NI) (Creswell, 2006). I assume the role of a participant/researched and researcher, and I personally relate my own story. Although this story depicts my struggles to overcome adversities during my career development (Bochner and Ellis, 2006), it is also influenced by the realisation that the dearth of lived accounts of successful Black female academic leaders in HE (Madsen, 2007) denies novice academics a chance to identify with role models. In particular, the story narrates personal experiences and insights by the participant within a complex context, and it highlights not only the problems I encountered, but also how I figured out how to persist and succeed amidst my struggles. The narrative is inward looking, detailing personal experiences, feelings and dispositions; and outward looking to explore influences of existential conditions emanating from the environment and its structural and cultural formations.

I also explore my interaction with various key social actors. I explore how their actions and framed assumptions and opinions of Black female academics have undermined me (Connelly and Clandinin, 1990). In order to analyse underlying causal factors affecting my work and development, use is made of Stierer's (2008) construct of reflexivity to delve into deeper meanings embodied within my experiences lived within a particular context. As I construct my narrative and examine the interplay between institutional culture(s), structures and my own agency, I also make explicit discourses that potentially undermine the potential of women to become leaders. I further highlight the taken-for-granted assumptions about the 


\section{'Mabokang Monnapula-Mapesela}

dearth of Black female academics in leadership positions in the South African HE system. According to Connelly and Clandinin (1990), narrative as the study of the ways human beings experience the world is both a phenomenon and a method, while the personal accounts of the story form the raw data. I make explicit what is implicit by revealing my understandings, interpretations and meanings of these experiences within the boundaries of my context.

As a participant researcher who believes that the owner tells a story better, I did not go into the field to collect the data, as I am the storyteller who is a member of the HE landscape (Clandinin, Connelly and Michael, 2000). The narrative inquiry in this paper is a case of my personally lived experience over seven years. It tells of my various encounters as a growing academic development leader who interacts with various institutional stakeholders (agents) in various formal and informal forums. Journal accounts of my experiences were kept from various institutional encounters with the structures, culture and key people, and these informed this inquiry. Those who know the structure of AD in most South African universities will agree that many AD practitioners have become 'jacks-of-all-trades'. They interact with nearly the entire university through meetings, workshops and committee work. Although there are many potential encounters to reflect on here, I have selected moments that were pertinent to my journey as it commenced as an AD leader in 2009.

I conclude the paper by arguing for a re-examination of the multi-layered institutional contexts - and in particular the constraining dominant culture and structural frames that underpin the academic enterprise, and debilitate the career advancement of Black female academics in leadership positions in South African universities.

\section{The beginning of my journey as an AD leader}

As a Black woman and a late entrant in academia, I started my academic career in a historically white Afrikaans university where I was inducted into the fields of Higher Education and academic development work. Although there was support from mentors within my department, generally life as a Black academic was not easy due to cultural stereotypes of race, gender, identity and language. These were used strategically and subtly to exclude Blacks. My transition from a traditional university to a university of technology was a cultural shock. The two universities and centres for academic development were significantly different in role and function, although there were firm commonalities in their strongly held beliefs and traditions due to their history.

On the first day of my new job in September 2009, a tall, well-dressed White man who had been acting in this position for nearly two years welcomed me. Prior to this, a White female professor had held the position. This man was one of the five White men who were soon to become my core team of directors as I became the substantive holder of the Dean's position. He took me to a big office with a boardroom and said:

This is your office, and those are the files about what goes on in this office (pointing at beautiful glass cabinet full of blue files).

Disregarding the development that occurred while I was an academic at my previous institution, to which I am forever indebted, this is how my journey as an academic leader 
began. It commenced with a short, but loaded, single narrative from a colleague. Thereafter the best induction came from my association with other knowledgeable people in various structures, at meetings and workshops. This too was never formalised. As I reflect on the brief introduction and induction that lasted a few minutes in my new office, I realise that it could not have been different, given the context at that time. In essence, I was the first Black female to take up the role of $\mathrm{AD}$ leader at the institution, and I was taking this job from a man whom I later came to learn had also tendered an application for the same position.

I understand why I had to find my way the hard way. Not only was I an alien, but a perceived stranger who robbed a deserving natural or traditional inhabitant (Naicker, 2013) of their job. Here I was disrupting the norm, as a Black woman leading White men in a historically White institution. The months and years that followed were not any easier, as I had to navigate my way through an environment which did not make any effort to reach out to me to offer or receive support. There was a culture of cold treatment and hostility, which could quickly place any newcomer in a place of isolation, which is often interpreted by sceptics as passiveness and lack of initiative (Naicker, 2013). Muberekwa and Nkomo's (2013) assertion that men remain dominant in higher education because of, among other things, patriarchal culture, and that they still act as gatekeepers for Black women's transition to positions of power, became a reality.

Staff in this new section held two different views, which they acted out whenever possible. A select few of these core staff displayed this cold treatment, hostility, as well as defiance of rules and instructions overtly and covertly, while others displayed their support by doing their jobs without resistance. However, even for this group, embracing change was not an option. Although the old structure and culture of AD had to change because of national and institutional transformation imperatives, they preferred to stay in their comfort zones and do things the traditional way. The dominant UoT culture was hard to disrupt. As I now reflect in hindsight, I realise that shifts in mind-set, and expectations of these staff to learn new things, such as how a university and the HE system function, were a tall order. Perhaps, as O'Connor (2010) argues, it could have been a case of conflicting power relations. Balance of power was impossible on grounds of gender and race. On the one hand, these men kept what they thought belonged to the men's club in close watch (O'Connor, 2016), while on the other hand, it could be that widened access for newcomers, especially Black women into their university, inflicted genuine fears of losing power. Such fears blinded them to embracing not only new people, but also new opportunities for development. All these challenges created invisible boundaries and subtle, but constraining undertakings, which made my success in this position less assured, or easy to attain.

Another aspect that still bedevils Black women in academia today is the stigmatisation that results from being defined as products of where they studied (structural shaping and modification) or by their race (cultural and ideological framing). This has resulted in the establishment of boundaries around legitimate knowledge and spaces for growth. Maton's (2014) argument that the knowledge sphere is restricted because no one can enter or ascend the knower structure unless they are already ideal knowers seems to best describe the perceptions of those who esteem themselves as natural inhabitants in the new university set up, especially in previously or historically White universities. Bluntly, one could say that Black academics are perceived as illegitimate knowers who have not earned 


\section{'Mabokang Monnapula-Mapesela}

the right to be in HE (Naicker, 2013). I believe it is only through the decolonisation of minds and deconstruction of assumptions that such ill-informed perceptions can be re-shaped and modified. Institutional cultures and sub-cultures are influential in creating the identities of various institutional occupants (D'Andrea and Gosling, 2005). In the university context, it is not only academics who provide frames about how they wish to be perceived and to conduct their business of teaching and learning, but also managers.

Two decades after the democratic elections, which have been characterised by intensive transformation efforts of the Higher Education system, certain groups of people still view themselves as separate. The group who claim to be the traditional stakeholders, i.e. Whites (and particularly White men), still cling to the notion that greater access for Black staff and students is a threat to quality and excellence of Higher Education (Mabokela and Magubane, 2004). These beliefs are also held by some academic development practitioners whose job it is to support students.

Black men, on the other hand, have extended the culture of patriarchy into one similar to the 'White supremacist and apartheid regime,' and are reserving and assigning superior status and positions only to themselves, always keeping a close eye on each other lest someone opens their ranks for infiltration by their lower-placed Black women counterparts. Mabokela (2012) argues that women in predominantly male-dominated organisations are constantly placed under psychological pressure and scrutiny from their colleagues. The persistence of inequality in Higher Education is not only peculiar to South Africa, but takes place across the globe, reflecting the pervasive structures of class, race and gender inequality (D'Andrea and Gosling 2005). According to these authors, this is because universities are social entities that function in the context of political, cultural and social inequalities. Universities usually maintain and legitimise this culture of inequality and condone the status quo, regardless of the pressure for change and transformation exerted on them by government.

Women, especially Black women who are always on the receiving end, are often deceived by the rhetoric echoed through policy that things will change, while in reality there is contradictory evidence of what is being enacted. Baatjes, Spreen and Vallys (2012) refer to this as a broken promise of the neoliberal restructuring of the South African higher education. Black female academics still endure intentional and unintentional actions aimed at labelling them as the 'underclass' and 'underperformers' who are not worthy to make it far in academia, let alone become academic leaders. Although post-1994, the South African democratic government has set many discourses in motion and developed a plethora of policies to address social inequality and development needs, two decades on universities are still plagued by what Badat (2015) terms an 'organic crisis' or an unfinished, 'tardy' transformation agenda. In many instances, equity policies remain merely 'theories' that are enacted in a preferential and tardy manner.

This is especially true at UoTs, where tribes, regimes and boundaries are established only to be penetrated by those with similar values and schema of thinking about power and authority and its association with masculine dominance for men and submissiveness for women. 


\section{Positioning myself as an AD leader}

Growing as a female academic leader of colour in the South African Higher Education system that is continuously undergoing transformation has been thus far a complex and lonely journey.

$\mathrm{AD}$ work in my institution is expansive and complex. It informs strategic change for teaching and learning and focuses on both staff and student academic support and development. AD practitioners are expected to have the requisite skills and knowledge to deal with all these issues, and to earn the respect of academics. The new expectation is that all AD work must be underpinned by a strong research and evidence base (CUT, 2013) rather than on common sense ideologies, ideas, assumptions and beliefs (Stierer, 2008; Maton, 2014, Quinn, 2012a). Senior AD staff in my centre are all expected by policy to possess doctorates as requisite qualifications, and should have a good understanding of teaching in HE, as well as a solid foundation of research into and engagement with HE. Quinn (2012a) views these attributes as pre-requisites for intellectual and strategic leadership for successful AD centres. Ironically, none of the permanent senior staff in the Centre has these attributes and as a result, exercising corporate agency is a challenge. This has had, and continues to have, negative implications, firstly for the development and promotion of a research culture as an underpinning principle for AD programmes. Secondly, this creates unequal power relations (Maton, 2014) between AD practitioners and lecturing staff whom they must support. For AD leaders, the AD work further entails actively participating in and reporting on $\mathrm{AD}$ activities to various committees (teaching and learning as well as support) and governance structures.

The AD staff, who are mostly on non-academic and on temporary contracts and who are studying to improve their qualifications, must do more with fewer resources under uncertain employment conditions (Altbach, 2000). Transformation to a fully-fledged university has resulted in many changes that are constraining to the functioning of the Centre. These include the relegation of AD staff to non-permanent contracts that has made the AD Centre volatile (Holt, Palmer and Challis, 2011), further by presenting a potential loss of the intellectual capital that has been accumulated over time. The executive management, who are key agents and actors in my institution, came to terms with the fact that the AD structure as discussed above was ineffective and therefore needed to be streamlined and aligned with the resources capabilities. There was also consensus that our AD must transcend what Tinto (2012) refers to as a laundry list approach or patchwork of disconnected actions towards academic support and development. In addition, it was necessary to ensure that the structure was suited to advance the emerging and espoused intents of the institution's new vision. For the past few years the limited resources of the Centre have been immensely strained, forcing staff, especially the AD leader, to do much more to maintain the reputation of the Centre and to achieve set annual targets.

In 2013, my line manager suggested that I should embark on a comprehensive benchmark of $\mathrm{AD}$ work because we needed to align our academic work with our new vision. I felt exhilarated. I was excited by the fact that I could now better influence changes in the existing structure and perhaps also the culture in my institution via this benchmark with the best in the country, and that I would be able to make proposals for improvement based on evidence. At last, I thought that I could earn respect for my Centre from the various stakeholders at the institution, especially for the hard work we do to support academics. 
Many unintended outcomes, most of which have been constraining rather than enabling, resulted from this benchmarking. In some cases, the status quo was maintained, resulting in no change (morphostasis) (Archer, 1996). The planned repositioning ended up being a restructuring, which resulted not only in renaming key positions, but also in a reduction of critical positions for responding to the required morphogenesis (change) (Archer, 1996)) as a university. This did not only have a negative impact on my role, but resulted in a culture of uncertainty and doubt about the value attached to AD work among AD staff who had hoped that the benchmarking would bring benefits. Generally, the value of AD at the institution is perceived with scepticism by some academics and managers. This is regardless of whether it sets the teaching and learning policy culture; introduces teaching, learning, and academic support projects and programmes; assists with curriculum design; solicits funding for teaching development; participates in various institutional committees and governance structures; or performs any other delegated functions. The benchmarking revealed a number of proactive stances for developing the identity and dignity of AD at South African universities. Common debates included the leadership of AD centres. At some universities, including my own, AD leaders held the title of a dean, while at many universities they are called directors (CUT Repositioning Document, 2013). CUT followed the latter by changing the position's title from dean to director. Many people who attach prestige to the former title regarded that stance as a silent demotion. On the one hand, I gave myself comfort by arguing that they are just pessimists, whilst, on the other hand, the decision taken by the institution contradicted our changed roles and functions.

In order to better position the AD staff to embrace some of the changes and to be better equipped to deal with the new demands, they were all encouraged to enrol in doctoral studies in their areas of work, while some have enrolled in postgraduate studies in higher education for academic developers (PGDip). Although this step is gradually paying dividends, in the meantime these practitioners have to try to do their jobs to the best of their abilities whilst being immersed in demanding study. This is very challenging for them, and perhaps even more challenging for me as the $\mathrm{AD}$ leader, as I must ensure that annual targets are met, and the quality of teaching and learning is upheld.

Additionally, as an $\mathrm{AD}$ leader, my role is to provide strategic leadership for $\mathrm{AD}$ work, ensure that the $\mathrm{AD}$ environment is enabling; that well-qualified $\mathrm{AD}$ staff are appointed, and that I work to develop corporate agency among AD staff in order to make AD work respected by academic staff. These duties are complex, and institutional contributions via supportive structures and culture would make them more achievable.

\section{Institutional efforts for support of Black female academics}

When I joined the institution in 2009, I became the only Black female professor at the institution, and since then the institution has been struggling to increase the number of Black female professors significantly.

In 2014, at a research seminar organised by the research division, I made an observation about the absence of Black female professors in the institution, and the poor efforts taken to support Black women. This prompted a hasty resolution to establish a mentorship programme for Black women, with the understanding that I would become a mentor for them. I immediately became a mentor by default rather than choice. This left me 
with a sinking feeling of hopelessness. Once again, the baton had been passed to me. The institution was extending my role without due consideration. I wondered whether I was genuinely viewed as a mentor who could add value, or whether I was perceived as a 'jack-ofall-trades' and 'panacea' for this particular ill. Nobody seemed to realise that I too still needed to be mentored to develop further.

\section{Enabling and constraining cultural elements}

In 2017, there are still a handful of Black female professors at my institution. This low representation of Black women in the professoriate has come with the unreasonable expectation that, since existing Black female professors are regarded as role models, we should mentor all Black women in the institution. 'The few available females frequently find themselves assuming the roles of mother, confidante, counsellor, friend or professional coach in addition to their professional responsibilities' (Mabokela, 2012). The reality is that, being an Associate Professor, my academic career is far from complete, and I too still need further mentoring and advancement. However, putting my development needs before those of others could earn me names such as the 'queen bee', and I could be accused of being territorial.

My further conflicting questions, some of which challenge my own integrity in this regard, are whether I should be burdened with the mentorship role when I also still need to be mentored, or whether I am selfish for even having such thoughts cross my mind? Are universities learning spaces for Black women in leadership positions? Do they create spaces for ongoing learning, mentorship and support for them? The answer is yes and no, as I draw from my own experiences and observations over the eight years that I have held a senior management position at my institution. On assumption of duties, many people expected me to be forever grateful, since this was a rare gift and honour for a Black woman to become an AD leader. Regardless of the accolades I received when embarking on this journey, the condescending lenses of these colleagues, especially men, did not view this acquisition as hard-earned. Maybe I read too much into their conduct, especially during the many meetings that I had to attend. I can recall one of my first formal meetings with executive and senior managers in 2009. This was the most humiliating meeting I have ever attended. Some of my colleagues were scolded like children, and were told that they had no right to be at the meeting. This particular executive continued to bully everyone at the meeting, even the Chairperson, who happened to be a woman. Following this, I vouched never to open my mouth in any of the senior management, Senate and other meetings, but another part of me fought back the fears that this executive had instilled in me. Still, I did not really ever feel that my voice at meetings really mattered. I attribute my survival to never letting myself to be turned invisible, humiliated or silenced.

Meetings act as structures for development. They unintentionally offer spaces for growth, although the culture is often patronising. One formalised development that was recommended by the institution was a leadership development programme for women in Higher Education in Southern Africa (HERS-SA) in 2011, where I was a guest speaker. Other than that, I have been responsible for designing my growth trajectory as an AD leader, through immersing myself in my work, and via benchmarking and identifying programmes at other $\mathrm{AD}$ centres in the country. I had to navigate my way through an environment which made no formal attempts to groom me for a leadership position (Naicker, 2013). Yes, my 
University provides funding as an enabling structure, but sensitivity and empathy to the needs and voices of Black women regarding their development are seldom given the seriousness they deserve. The overall culture is that of personal autonomy, individual responsibility and independence over one's career path advancement. The onus lies entirely on women as individuals to find opportunities which are worthwhile, and to find mentors and communities of practice for in-situ learning outside the institution, as my institution, like other small universities, especially smaller UoTs, have few willing mentors. The few potential mentors are often the same people who establish invisible structural boundaries for the few Black women who present themselves as worthy of reaching higher echelons.

\section{Developing an enabling environment}

I mentioned earlier that the institutional structures and culture are not always supportive. We all must find time to pursue further studies or to do research amidst the complexities. There are not many mentors in the system for AD staff, and especially for Black female academics in my institution, and therefore the development and career advancement of Black women in the academia is almost solely their own responsibility. As an AD leader, I have a responsibility, not only for myself, but also for the growth and development of other staff AD staff and academics, including Black women.

Apart from the fact that the institution, upon realising the capacity shortcomings of academics, resolved that all academics must be developed as professional teachers, since 'good teaching' can make a difference, and it is not an intuitive activity. I came to realise that $\mathrm{AD}$ is also not an intuitive activity, but only competent academic developers can make a difference in guiding academics. The strategy of once-off training and development workshops for these groups was therefore less effective in enhancing teaching and learning, and $\mathrm{AD}$ work. I needed to attend a more structured course such as postgraduate diploma programme in Higher Education that would enable a longer-term, sustained engagement with issues of teaching, learning and $\mathrm{AD}$, and consequently cumulative learning for the $\mathrm{AD}$ team, academics and myself (Maton, 2014). A longer-term development approach is supported by Quinn (2012b:28), who asserts that

professional development...has the potential to disrupt lecturers' taken-for-granted assumptions about teaching and learning, and can further equip them to provide educational offerings that result in more equitable outcomes for students, thus contributing to the transformation of higher education in South Africa and beyond.

Thus, one of the things I did to create an enabling environment was to solicit funding (as a structure) for the institution from the DHET's Teaching Development grant to create opportunities for academics to professionalise their practice as university teachers, and for AD staff to professionalise their work as AD practitioners. I had to lead by example by enrolling in a PGDip programme.

\section{Demeaning encounters with some key stakeholders: fighting to gain recognition}

It is customary in my institution for senior management positions to be five-year fixed term contract positions that are renewable based on performance. In 2014 my contract was 
therefore due for renewal. As normal, processes for contract review and renewal were initiated by the relevant structure. This became a long and arduous process. I was surprised when in the following year, already a year after the contract had ended, I was recalled from a teaching and learning conference I was attending, but at the same time, I was excited that I would finally receive a verdict on the pending renewal of my contract. As I sat down in front of the two most senior managers at the institution, I was told:

We have decided not to renew your contract, but...

Many reasons were put forward for this decision. I was shocked, I felt humiliated, undermined and disrespected; but it became clear to me that there were hidden agendas. Perhaps someone was looking for a needle in a haystack to justify not extending the contract regardless of the positive results of the institution's performance management for the previous years. This decision also overruled the recommendations of several governance structures and stakeholders. Thereafter the contract was extended several times, in bits and pieces of time lasting one year, six months, three months, etc., until its final renewal two years later. It became apparent that many key people were developing new parameters for this kind of exercise along the way. Instead of the commonly known procedure being followed, new procedures emerged and new structures - Senate committees, unions, etc. had to pronounce themselves on my eligibility. Many requirements and expectations emerged at this point and were used as guises for exclusion. These became new rules that were obviously set in line with the accolades of those who were favoured for the positions. However, these rules were often not based on constitutions or regulatory frameworks. They were part of an unwritten culture.

I encountered many painful demeaning moments with many institutional structures. Whilst I wanted to believe that they probably thought they were inducting me into the job as a senior manager, their swim-or-sink approach and constant tests made me wonder whether I was not being set up for failure as a woman. During the time that followed, I made an undertaking to focus on my professional development and to do my job to the best of my ability. I had to exert my own agency in the face of a debilitating, tacit culture that seemed bent on keeping me 'in my place' rather than enabling my advancement.

\section{Improving myself through professional development}

Apart from continuing to conduct research and publish my work, in January 2016 I enrolled in a two-year PGDip for academic developers. This was motivated by a need to refresh my knowledge of $\mathrm{HE}$ as a field of study, and to better situate myself as an academic development leader. Quinn (2012b) argues that AD leaders must have requisite personal properties and powers to provide strategic leadership on teaching and learning, as well as on academic development matters in their units and within the entire institution. My line manager endorsed my decision, but my immediate colleagues and AD staff did not. At one of our regular staff meetings, I reported that I would be enrolling in the PGDip. One of my AD staff who had enrolled in the PGDip a year earlier looked at me in amazement and remarked: 
Prof, what more do you want? You are a professor and dean of a section! What more do you think you will get from the programme? You surely know these things! You are wasting time that you could put to better use.

This person, like many others, wondered why a professor would enrol in a PGDip programme, and found it odd that I had done so. Some questioned what else I needed in life, and assumed that, as a Black female professor, I had reached my ultimate growth and therefore needed no more.

These kinds of perceptions implied that as a Black woman. I was transgressing the invisible boundaries set for advancement of Black women (Mabokela \& Magubane, 2004). However, I saw my decision as not only improving my Personal Emergent Properties (PEPs) (Archer, 1995), but also consciously exercising my powers as an AD leader and growing my agency by ensuring that I am not confined within the marginalised position which I currently occupy in my institution. Agency is a manifestation of established dominant structures (material things and interests) and culture (a set of values, ideologies, beliefs, theories and philosophies) (Archer, 1996). It relates to individual people's roles and responsibilities within given contexts. According to Archer (1996), in any social organisation, agency will comprise two types of key agents, namely primary agents with no properties and powers to change their contexts, and corporate agents who possess powers and properties to change their contexts. Archer (1996) argues that the latter are groups of people with clear intentionality to re-shape or retain the status quo in their environment. They have a clear agenda about what they want, and they organise themselves to achieve their goals.

The PGDip programme provided an ideal learning space - a community of practice led by some of the best AD practitioners and leaders in the country whose experience in $\mathrm{AD}$ work is acknowledged globally. This PGDip is not only a community of practice, but what D'Andrea and Gosling (2002) refer to as a meta-learning community. The programme provides space for situated learning; for social interactions with peers and knowers in the field; a place where we could challenge underlying assumptions and philosophies informing our own practice(s) as AD practitioners; and a space to be critical reflexive practitioners who integrate the theory underpinning teaching and learning into our daily roles. The programme provided a space where participants could interrogate important theories and concepts, which affect students' learning and hinder epistemological and ontological access. This enhances understanding of the needs and contextual factors of our diverse students, as well the real reasons for high attrition rate. Briefly, the PGDip grooms HE and AD corporate agents. Thus, being able to reflect critically on my practice in the manner that this programme facilitates, and to integrate theory and practice to solve various problems and challenges relating to $\mathrm{AD}$ and teaching and learning in my University, is well worth two years of my time, and enhances my ability to promote the exercise of similar agency in others, especially Black women.

\section{Conclusion}

Many people believe that the abolition of apartheid and the systemic transformation of Higher Education in South Africa has resulted in nothing but supportive structures and cultures for all. They assume that these will effect meaningful transformation on their own. 
By using Archer's framework, I have come to realise how traditional values, ideas, beliefs and theories have shaped the identity of my institution and its stakeholders, causing stagnation and resistance to morphogenesis, or transformation (Archer 1995). I am now aware of the various forms of institutional and disciplinary culture and academic identities that frequently constrain the transformation of Black women into academic leaders. D'Andrea and Gosling (2005) argue that, because of the diversity of interests, values and academic sub-structures that exist within any one university, achieving willingness to change across the institution and ensuring shifts in the mental models that underpin various practices is a complex and difficult matter for those in AD leadership.

According to D'Andrea and Gosling (2005:61), it is important to identify social groupings that may resist change out of fear that any proposed change may undermine the values, standards and 'regulative discourses' of those social groups and disciplines. The same social orders can, however, be used to facilitate the process of change. Moreover, environments that respect and devote efforts aimed at providing equitable opportunities to male and female academics alike should be created. Such a culture shift should enable women to realise their full potential without prejudice. Marginalised groups, such as Black women academics and leaders, should also realise that the social world has different types and forms of boundaries: the physical, which we see, and the invisible, which are just as real, but harder to see. They should recognise these intangible illusive boundaries as an everpresent reality, but not be deterred from taking ownership of their career advancement. I also make a case for government and universities to re-examine institutional cultures and values for existence of dominant frames that constrain career advancement of female academics to leadership positions.

I urge Black female academics to perceive themselves as agents of their own change and designers of their own career paths who should view constraints such as resistance, disadvantage, oppression, psychological pressure and scrutiny, bullying and segregation through different lenses. They need to make efforts to turn their own disadvantages into potential opportunities. Archer's (1996) argument of the power of agency present in all human beings offers a useful frame to make a case that we can succeed if we take time to deliberate on our social circumstances and personal concerns within our work contexts, and work towards greater corporate and collective agency in changing the dominant cultures that would seek to hold us back.

'Mabokang Monnapula- Mapesela is an Associate Professor in Higher Education and the Director for the Centre for Innovation in Learning and Teaching at the Central University of Technology, Free State. She holds a PhD in Higher Education and has published articles and book chapters on various aspects of Higher Education. Her areas of work and interest include students' learning and success, curriculum design and development, scholarship of teaching and learning, as well as higher education transformation. 


\section{References}

Altbach, P.G. 2000. Academic freedom in Hong Kong: Threats Inside Out. The International Journal of Higher Education, 21: 9-10.

Archer, M. 1995. Realist social theory: the morphogenetic approach. Cambridge: Cambridge University Press.

Archer, M. 1996. Culture and agency: The place of culture in social theory. Cambridge: Cambridge University Press.

Baatjes, I., Spreen, C.A., \& Vallys, S. 2012. The broken promise of neoliberal restructuring of the South African Higher Education. In Pusser, B., Kemper, K. Marginson, S. \& Ordorika, I. (eds.) Universities and the Public Sphere: Knowledge Creation and the State building in the Era of Globalisation. New York: Taylor \& Francis.

Badat, S. 2015. The South African education student protests of 2015: Notes towards an investigation. Unpublished Draft Paper.

Bhaskar, R. 1989. Reclaiming Reality: A Critical Introduction to Contemporary Philosophy. London: Verso.

Bochner, A. \& Ellis, C. 2006. Communication as autoethnography. In Sherperd, G.J., St John, J. and Striphas, T. (eds). Communications a Perspectives on Theory. Thousand Oaks, CA: Sage, 110-122.

Boughey, C. \& McKenna, S. 2015. Analysing an audit cycle: a critical realist account. Studies in Higher Education, 42(6): 963-975.

Central University of Technology. 2014. CUT Academic Plan 2014-2020. Bloemfontein: Central University of Technology.

Central University of Technology. 2016. Annual Report. Unpublished Document, Bloemfontein: Central University of Technology.

Clandinin, D.J. \& Connolly, F. 1999. Shaping a Professional Identity: Stories of Educational Practice. London: Alhouse Press.

Clandinin, D.J. \& Connolly, F. 2000. Narrative Inquiry: Experience and Story in Qualitative research. San Francisco: Jossey-Bass.

Creswell, J.W. 2006. Qualitative Inquiry and Research Design: Choosing among Five Approaches. $2^{\text {nd }}$ Ed. Thousand Oaks, CA: Sage

D'Andrea, V. \& Gosling, D. 2005. Improving teaching and learning in Higher Education: A whole institution approach. New York: SRHE and Open University Press.

DoE. 1997. Education White Paper 3. A programme for the transformation of higher education. Pretoria: Department of Education.

Donati, P. 2011. Relational sociology: A new paradigm for the social sciences. Abingdon: Routledge.

Du Pre, R. 2009. The Place and role of Universities of Technology in South Africa. Durban: Durban University of Technology.

Harvey, L. 2006. Understanding quality, and Introducing Bologna objectives and tools. In Purser, L. (ed.), EUA Bologna Handbook: Making Bologna work. Brussels European University. Association and Berlin, Raabe.

Holt, D., Palmer, S. \& Challis, D. 2011. Changing perspectives: teaching and learning centres' strategic contributions to academic development in Australian higher education. International Journal for Academic Development, 16(1): 5-17. 
Luckett, C. 2010. A 'Quality Revolution' Constrained? A Critical Reflection on Quality. Assurance from the South African Higher Education Context. Quality in Higher Education, 16(1): 71-75.

Mabokela, R. \& Magubane, Z. 2004. Hear our voices: Race, gender and status of black South African women in the academy. Pretoria: Unisa Press.

Mabokela, R.O. 2012. Negotiating Race in the Knowledge Age: The Case of South African Universities. In Pusser, B., Kemper, K. Marginson, S. and Ordorika, I. (eds.) Universities and the Public Sphere: Knowledge Creation and the State building in the Era of Globalisation. New York: Taylor \& Francis.

Mainah, F. 2016. The Rising of Black Women in Academic Leadership Positions in the United States of America. Unpublished doctoral dissertation, Chicago School of Professional Psychology, USA.

Maton, K. 2014. Knowledge of the knowers: Towards a realist sociology of education. London: Routledge.

Morrow, W. 1993. Entitlement and achievement in education. Studies in Philosophy and Education, 13(1): 33-47.

Naicker, L. 2013. The journey of South African women academics with particular focus on women in theological education. Studia Historiae Ecclesiasticae, 39(1): 325-336.

O'Connor, P. 2010. Is senior management in Irish Universities male-dominated? What are the Implications? Irish Journal of Sociology, 18(1):1-21.

Quinn, L. 2012a. Introduction. In Quinn, L. (ed.) Re-Imagining academic staff development: spaces for disruption. Stellenbosch: SUNPress, 1-13.

Quinn, L. 2012b. Enabling and constraining conditions for academic staff development. In Quinn, L. (ed.) Re-Imagining academic staff development: spaces for disruption. Stellenbosch: SUNPress, 36-50.

Ramphele, M. 2008. Laying ghosts to rest: Dilemmas of the transformation in South Africa. University of Michigan: NB Pub Limited.

South Africa. Council on Higher Education (CHE). 2016. South African Higher Education Reviewed: Two decades of Democracy. Pretoria: CHE.

Stierer, B. 2008. Learning to write about teaching: understanding the writing demands of lecturer development programmes in higher education. In Murray, R. (ed.) The Scholarship of teaching and learning in Higher Education. England/New York: Society for Research into Higher Education \& Open University Press, 34-45.

Tinto, V. 2012. Completing college rethinking: Institutional action. Chicago and London: The University of Chicago Press.

Walker, M. 1998. Academic Identities: Women on a South African Landscape. British Journal of Sociology of Education, 19: 335-354.

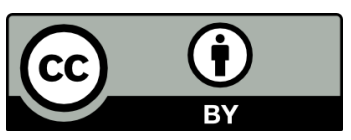

This publication is covered by a Creative Commons Attribution 4.0 International license. For further information please see: http://creativecommons.org/licenses/by/4.0/. 